\title{
Determinants of E-invoice Adoption: Empirical Evidence from Vietnam*
}

\author{
Anh Huu NGUYEN ${ }^{1}$, Thao Phuong NGUYEN², Giang Tra Thi DANG ${ }^{3}$
}

Received: April 30, 2020

Revised: May 03, 2020

Accepted: June 07, 2020

\begin{abstract}
This paper aims to investigate the effect of the factors on the e-invoice at its infant stage of adoption in the context of Vietnam. Data were collected by using a questionnaire delivered to 318 participants who are managers and accountants of companies in Vietnam from June to September 2019. The statistical methods approaches are employed to address the research issues including Cronbach's Alpha testing, Explanatory Factor Analysis (EFA), and Confirmation Factor Analysis (CFA). Then, Structural Equation Modeling (SEM) is employed to assess the proposed hypotheses model of e-invoice adoption in Vietnam. The research findings showed that direct factors have a statistically significant impact on the e-invoice adoption towards behavior, and perceived behavioral control. Perceived usefulness and perceived ease-ofuse positively affect attitude towards the behavior. These factors, in turn, are impacted by perceived compatibility. Based on the research results, some practicable suggestions are proposed in order to boost the number of Vietnamese enterprises voluntarily adopting e-invoice. This study indicates the important impacts of the user's attitude and perception about control ability on intention to use. In addition, some key intuitive recommendations were proposed aiming to improve the success of the e-invoice adoption of enterprises in the context of Vietnam.
\end{abstract}

Keywords : E-invoice, Adoption, Innovation Diffusion Theory (IDT), Technology Acceptance Model (TAM), Theory of Planned Behavior (TPB)

JEL Classification Code: G30, G32, M41, M48

\section{Introduction}

In recent years, business information systems and activities have been changing rapidly due to the revolution of information technology. Globalization opens up new ways to develop technology for developing countries. Currently, many

*This research is funded by the National Economics University (NEU), Hanoi, Vietnam. The authors thank anonymous referees for their contributions and the NEU for funding this research.

${ }^{1}$ First Author and Corresponding Author. Dean, School of Accounting and Auditing, National Economics University, Vietnam [Postal Address: 207 Giai Phong Road, Dong Tam Ward, Hai Ba Trung District, Hanoi, 113068, Vietnam] Email: anhnh@neu.edu.vn

${ }^{2}$ Lecturer, School of Accounting and Auditing, National Economics University, Vietnam. Email: thaonp42@gmail.com

${ }^{3}$ Lecturer, School of Accounting and Auditing, National Economics University, Vietnam. Email: giangtra.neu@gmail.com

(c) Copyright: The Author(s)

This is an Open Access article distributed under the terms of the Creative Commons Attribution Non-Commercial License (http://Creativecommons.org/licenses/by-nc/4.0/) which permits unrestricted noncommercial use, distribution, and reproduction in any medium, provided the original work is properly cited. countries have broad access channels to new technologies and their applications (Dnishev \& Alzhanova, 2016). Various types of businesses such as e-commerce or online services have been developed to meet the market's demands. Consequently, new digital applications, which allow improving online services, are urgently needed. According to Tuan, Thanh and Loc (2018), in order to achieve sustainable development, Vietnamese enterprises need to apply technology in all aspects of the business, and identify technology as a key factor in determining the competitiveness and development of enterprises in the integration process. E-invoice is one of the applications that help to enhance business activities since it can issue and received automatically information about business transactions under an electronic form via the Internet. Apparently, e-invoice adoption is necessary to enhance the efficiency and effectiveness of business operations. Nevertheless, the government is also concerned with the e-invoice adoption since it is one of the most efficient and transparent instruments for the tax administration. E-invoice adoption will help the tax authorities to strengthen the inspection of tax declarations, tax payments, and tax refunds of firms (Nguyen, Pham, Le, Truong, \& Tran, 2020). 
The adoption of e-invoice obviously brings a number of potential benefits, including: reducing time to process transactions, saving the cost of operating, enhancing human resources efficiency, and optimizing the operation of other IT application systems such as e-commerce, online services, and online tax. Acknowledging the advantages as well as the necessity of e-invoice to develop efficient e-government, Vietnam's Ministry of Finance encouraged the adoption of e-invoice by issuing decree No. 51/2010/ND-CP in 2010, which officially recognizes the existence of e-invoice. The government approved the e-invoice adoption procedure, which aims to make e-invoice compulsory for all enterprises from November 2020.

However, according to the report by Vietnam Chamber of Commerce and Industry (VCCI), there were only 3,000 enterprises, approximately $5 \%$, that had used e-invoice in Vietnam till January 2018. It implies that e-invoice adoption in the country is at an extremely low level regardless of the constant encouragement as well as the aggressive pressure of the Vietnamese government. To ensure that the government would accomplish the proposed objective, it is necessary to discover determinants of e-invoice adoption at an infant stage in Vietnam. Since e-invoice is based on Internet technology, innovation diffusion theory (IDT) and technology acceptance model (TAM) are employed to investigate technological system aspects that affect the acceptance of e-invoice. However, IDT and TAM model is not sufficient to capture the roles of an individual and social system in the intention to adopt internet-based application (Teo, 2001; Wu \& Chen, 2005). Therefore, the theory of planned behavior (TPB) is brought in to enhance the predictability of the research model.

The main objectives of this paper are to discover the critical factors that impact on the adoption of e-invoice in Vietnam at an infant stage and to propose a research model that allows the estimation of the relationship between these factors. The combination of IDT, TAM and TPB is the basis for the research model, which is evaluated by employing SEM analysis. Practically, the research results will provide a deep insight on the intention to adopt e-invoice in Vietnam.

This paper consists of six sections. Following the introduction, Section 2 describes the theoretical framework. Sections 3 describes literature review and hypothesis development. Section 4 explains the data collection and the research methodology. Section 5 presents empirical results and discussion. Finally, Section 6 provides some recommendations and concluding remarks.

\section{Theoretical Framework}

\subsection{Innovation Diffusion Theory (IDT)}

According to Rogers (1995), the process of adopting innovation and making decision towards it was different among five groups of individual: innovators, early adopters, early majority, late majority and laggards. This theory suggested that the degrees of willingness to adopt new technology were affected by five key factors: (1) Relative advantage: the degree of superior benefits of new product over the existing products; (2) Compatibility: the degree of innovation is to be consistent with existing values, experiences and needs of users; (3) Complexity: the degree of difficulty to understand, learn and employ new technology; (4) Trialability: The degree of innovation is to be experienced before being applied; and (5) Observability: the ability of users to observe the result of the innovation.

\subsection{Technology Adoption Model (TAM)}

TAM was proposed by Davis, Bagozzi, and Warshaw (1989); it determines the factors that affected to user acceptance of information technology. This model examined the relationship between Perceived usefulness (PU), Perceived ease-of-use (PEOU) and Attitude towards adopting a specific technology. Perceived ease-of-use is defined as the perception of a person that using a particular technology will be effortless. Perceived usefulness reflects the belief of a person that their productivity will be enhanced when adopting a specific information technology (Davis, Bagozzi \& Warshaw, 1989). These factors are assumed to be determinants of a person's attitude towards the technology. It is noticed that factors "Relative advantage" and "Complexity" which is mentioned in IDT is equivalent to "Perceived usefulness" and "Perceived ease of use" concepts in TAM, respectively.

\subsection{Theory of Planned Behavior (TPB)}

This theory posits that an individual's behavior is directly affected by behavioral intention, which is in turn jointly impacted by Attitude, Subjective Norm, and Perceived Behavioral Control (Ajzen, 1991). Attitude refers to the assessment of an individual towards questioned behavior. Subjective Norm is the belief of an individual that significant people's perception on a behavior under consideration would affect his performance. Perceived Behavioral Control is the indication of an individual's awareness regarding the degree of ease or difficulty in engaging a behavior in question (Ajzen, 1991). An individual will likely have intention to perform a certain behavior if he or she perceives positive assessment towards the behavior. Furthermore, if the person trusts that important people approve the behavior, his motivation to behave will be increased. Finally, the intention to perform the considered behavior should be stronger if given resources such as knowledge, experience allow an individual to accomplish the behavior without any difficulty. 
Anh Huu NGUYEN, Thao Phuong NGUYEN, Giang Tra Thi DANG /

\section{Literature Review and Hypotheses}

There are several studies that explore factors affecting the adoption of e-invoice. Hernandez-Ortega (2012) employed the combination of IDT and TAM to investigate key factors of e-invoice adoption in Spain at firm level for both non-users and adopters. The results indicated that perceived usefulness, perceived ease-of-use, and perceived compatibility played a critical role in e-invoice adoption for both groups. Perceived security was considered to be determinant of intention to use e-invoice for the first time. However, this factor was no longer significant for existed adopters' intention.

The study by Lian (2015) was based on the Unified Theory of Acceptance and Use of Technology 2 (UTAUT2) to understand the determinants of e-invoice adoption in Taiwan. Effort expectation, social influence, trusts in e-government and perceived risks were indicated as key factors affected the intention to adopt e-invoice. The result also implied that security concerns regarding e-government significantly influenced trust in e-government and perceived risk factors. In sum, none of published study has investigated the factors that influence the extent of e-invoice adoption in Vietnam. This gap is a stating point for this study.

Previous studies found that attitude has positive effect on intention (Taylor \& Todd, 1995; Bhattacherjee, 2000; Wu \& Chen, 2005; Gopi \& Ramayah, 2007; Ajzen, 2015; Samad, 2018; Rahi, Ghani, Alnaser, \& Ngah, 2018). In this study, we assume that positive attitude towards e-invoice motivates the users to adopt e-invoice. Therefore, the following hypothesis is formulated:

Hypothesis 1: Attitude towards using e-invoice has a positively effect on intention to use e-invoice

Subjective norm ( $\mathrm{SN})$ is considered as one of the main determinants of intention to use technology in TPB model. It can be predicted that, if an individual perceives the social strain of performing behavior under consideration, he or she will have stronger motivation to perform. This relation has been confirmed by numerous researchers, such as Taylor and Todd (1995), Bhattacherjee (2000), Wu and Chen (2005), Gopi and Ramayah (2007), Ajzen (2015), Lian (2015), Samad (2018). In this paper, the proposed hypothesis related to subjective norm is:

Hypothesis 2: Subjective norm positively has a positive effect on intention to use e-invoice

Belief of an individual about his or her resources and opportunities to engage in the behavior under consideration is defined as perceived behavior control (PBC). The TPB (Ajzen, 1991) proposed that intention to perform the behavior would be stronger if an individual perceives the availability of resources and fewer obstacles to undertake the performance. Prior studies determined the positive relationship between perceived behavior control and intention to behave (Taylor \& Todd, 1995; Bhattacherjee, 2000; Wu \& Chen, 2005, Gopi \& Ramayah, 2007; Ajzen, 2015; Samad, 2018). Rahi, Ghani, Alnaser and Ngah (2018) suggested that a facilitating condition, which is defined similar to perceived behavior control, positively influenced adopter intention. This paper infers that, if an individual believes he or she can control resources (knowledge, experiences, instruments) and opportunities to adopt e-invoice, the intention to perform behavior will become more expected. Thus, the following hypothesis is proposed:

Hypothesis 3: Perceived behavior control has a positive effect on intention to use e-invoice

The TAM proposed that attitude towards using information technology is affected by the users' perceptions about technology's advantages and the degrees of difficulty to understand and to apply it. According to Davis (1989), an individual normally tends to adopt new information technology if he or she recognizes its benefits. Nevertheless, if the technology needs extra effort to learn or to employ, it may negatively affect the willingness of adopting. HernandezOrtega (2012), Renny, Guritno and Siringoringo (2013) indicated that perceived usefulness and perceived ease of use positively affect intention to use technology. However, Lian (2015) concluded that only perceived usefulness influences intention to behavior. The positive effects of PU and PEOU on attitude towards using online- tax were documented in the study by $\mathrm{Wu}$ and Chen (2015). Rahi, Ghani, Alnaser and Ngah (2018) indicated that performance expectancy and effort expectancy, which are identical to perceived usefulness and perceived ease-of-use respectively, had positive effects on intention to adopt Internet banking. In this study, e-invoice is considered as a new type of information technology application; therefore TAM can be applied to investigate the adoption of this phenomenon. This paper assumes that useful information about adopting e-invoice and the degrees of difficulty in adopt e-invoice determine the attitude towards the e-invoice adoption. Therefore, these hypothesizes are inferred:

Hypothesis 4: Perceived usefulness has a positive effect on attitude towards using e-invoice

Hypothesis 5: Perceived ease of use has a positive effect on attitude towards using e-invoice

Five factors are considered to affect an individual's process of adopting innovation in IDT. However, recent studies indicated that only three factors, including relative advantage, compatibility, and complexity were persistently 
impacting individuals in adopting innovation process (Kolodinsky, Hogarth \& Hilgert, 2004; Kumpajaya \& Dhewanto, 2015). Perceived compatibility was indicated that having an important role on perception of users about the degrees of usefulness and ease of use (Quaddusa \& Achjari, 2005; Ismail, 2016). Kanchanatanee, Suwanno and Jarernvongrayab (2014) also emphasized the critical influence of perceived compatibility not only on perceived usefulness and perceived ease of use, but also on intention to behavior. Hernandez-Otega (2012) found that this factor positively impacted on intention of users. In this paper, we infer that if e-invoice system is more consistent with existed values and resources of users, it will be considered to provide higher usefulness and lower degrees of difficulty to apply. The proposed hypothesizes related to perceived compatibility, therefore, are:

Hypothesis 6: Perceived compatibility has a positive effect on Perceived usefulness

Hypothesis 7: Perceived compatibility has a positive effect on Perceived ease-of-use

Security is a critical factor should be thoroughly considered when an individual intent to adopt any technology service or product. Perceived security is the perception of users about degrees of being protected from threats (Yousafzai, Pallister \& Foxall, 2003). Prior studies indicated the positive relationship between security and user intention (Hernandez-Ortega, 2012; Kassim, 2017; Jun \& Jaafar, 2011). Related to e-invoice, security requirements should be strictly complied with since it enhances the reliability of transactions. We propose that if a user perceives being protected from threats, the attitude towards using e-invoice will be more positive. Therefore, the inferred hypothesis is:

Hypothesis 8: Perceived security has a positive effect on Attitude towards using e-invoice

\section{Data and Research Methodology}

\subsection{Data Collection}

Constructed variables for this paper were developed based on previous studies, including the intention to adopt e-invoice, attitude towards using e-invoice, subjective norm, perceived behavioural control, perceived usefulness, perceived ease-of-use, perceived compatibility and perceived security. A five-point Likert scale, with 5 being "Strongly agree" and 1 being "Strongly disagree", was employed to measure variables since it was suggested that the difference between 5-point scales and 7-point scales is trivial (Dawes, 2008; Nguyen, Ha \& Nguyen, 2020).
The measurements of variables were inferred based on the existing literature. Modifying prior studies to fit the extent of Vietnamese enterprise developed a total of 27 items. The measurements and related references for each item are listed in Table 1.

A questionnaire survey was developed to collect data for this study. The voluntary participants were managers or accountants of companies in Vietnam. Data were obtained from June to September 2019 and a total of 318 valid complete surveys were received. According to Hair, Black, Babin and Anderson (2009), the minimum sample size required to perform confirmatory factor analysis (CFA) is computed by multiplying five times the observed variables. In this paper, the number of observed variables was 27 , therefore, the minimum sample size complied with the suggestion of Hair, Black, Babin and Anderson (2009) is 135. Thus, the obtained sample was considered to be adequate for analysis. Similar to the research of Ha (2020), the collected data is processed using SPSS 23 and AMOS 23 software including statistics, Cronbach's Alpha reliability assessment, analysis of EFA, CFA factors and SEM linear structure model to analyze the factors affecting the e-invoice at its infant stage of adoption in Vietnam.

\subsection{Research Model}

Based on the combination of IDT, TAM and TPB models as well as the above-mentioned literature review, the research model to investigate the intention to adopt e-invoice in Vietnam is generated as follows (see Figure 1):

The proposed model of this paper is estimated by structural equation modeling (SEM). The following tests will be applied to determine the goodness of measures and model:

Cronbach's Alpha is tested to estimate the reliablity of scales. An observed variable is ensured reliable if Corrected item-total correlation $\geq 0.3$ and Cronbach's Alpha $\geq 0.6$ (Nunnally \& Bernstein, 1994).

Explanatory factor analysis (EFA) is employed to explore the relationship among measured variables and identify some of scales. This analysis aims to identify the latent variables which used to explain the sample's observed variance and co-variance (Jain \& Ajmera, 2018). Yanamandram \& White (2006) suggested that the scales will be valid if $\mathrm{KMO} \geq 0.5$ and Barlett's test value $\leq$. The eigenvalue is considered to determine the appropriate number of scales. Those with that Eigenvalue $\geq 1$ will be retained for the model (Yanamandram \& White, 2006).

Confirmation factor analysis (CFA) focuses on verifying the factor structure of observed variables and testing the fitness of measurements of real data. The goodness of fit, reliability test, unidimensionality, convergent validity and discriminant 
Table 1: Measurements of variables

\begin{tabular}{|c|c|c|}
\hline Variables & & Items \\
\hline \multirow{4}{*}{$\begin{array}{l}\text { Perceived usefulness (PU) } \\
\text { (Venkatesh, Morris, Davis \& Davis, 2003; } \\
\text { Davis, 1989) }\end{array}$} & PU1 & $\begin{array}{l}\text { Processing time of e-invoice is reduced in compared } \\
\text { with paper invoice }\end{array}$ \\
\hline & PU2 & Work efficiency is enhanced by using e-invoice \\
\hline & PU3 & $\begin{array}{l}\text { Using e-invoice increases the convenience of } \\
\text { transactions }\end{array}$ \\
\hline & PU4 & $\begin{array}{l}\text { Costs of processing transactions are optimized by using } \\
\text { e-invoice }\end{array}$ \\
\hline \multirow{4}{*}{$\begin{array}{l}\text { Perceived ease of use (PEOU) } \\
\text { (Venkatesh \& Davis, 1996, 2000) }\end{array}$} & PEOU1 & It is effortless to learn how to use e-invoice \\
\hline & PEOU2 & It is easy and clear to process e-invoice \\
\hline & PEOU3 & It is effortless to remember how to use e-invoice \\
\hline & PEOU4 & Implement of e-invoice is simple \\
\hline \multirow[t]{3}{*}{$\begin{array}{l}\text { Perceived compatibility (PC) } \\
\text { (Premkumar \& Roberts, 1999) }\end{array}$} & PC1 & $\begin{array}{l}\text { Using e-invoice is accordant with the company's value } \\
\text { and belief }\end{array}$ \\
\hline & PC2 & Using e-invoice is accordant with the company's culture \\
\hline & PC3 & $\begin{array}{l}\text { Using e-invoice is accordant with the company's } \\
\text { activities }\end{array}$ \\
\hline \multirow{3}{*}{$\begin{array}{l}\text { Perceived security (PS) } \\
\text { (O`Cas \& Fenech, 2003; Pikkarainen, } \\
\text { Pikkarainen, Karjaluoto \& Pahnila, 2004; } \\
\text { Ranganathan \& Ganapathy, 2002) }\end{array}$} & PS1 & $\begin{array}{l}\text { Transactions are safety recorded and transmitted by } \\
\text { using e-invoice }\end{array}$ \\
\hline & PS2 & $\begin{array}{l}\text { Data is kept confidential by the third parties (who supply } \\
\text { e-invoice services) }\end{array}$ \\
\hline & PS3 & The e-invoice is not easily tampered with \\
\hline \multirow{4}{*}{$\begin{array}{l}\text { Attitude towards behavior (AB) } \\
\text { (Taylor \& Todd, 1995; Bhattacherjee, 2000) }\end{array}$} & $\mathrm{AB} 1$ & Using e-invoice is considered as a good idea \\
\hline & AB2 & Using e-invoice is a wise idea \\
\hline & AB3 & I support the idea of using e-invoice \\
\hline & AB4 & Using e-invoice is a fascinating experience \\
\hline \multirow[t]{3}{*}{$\begin{array}{l}\text { Subjective norm (SN) } \\
\text { (Taylor \& Todd, 1995; Bhattacherjee, 2000) }\end{array}$} & SN1 & $\begin{array}{l}\text { My friends and my family think that I should adopt } \\
\text { e-invoice }\end{array}$ \\
\hline & SN2 & $\begin{array}{l}\text { People who influence me think that I should adopt } \\
\text { e-invoice }\end{array}$ \\
\hline & SN3 & $\begin{array}{l}\text { People whose opinions are valued think that I should } \\
\text { adopt e-invoice }\end{array}$ \\
\hline \multirow[t]{3}{*}{$\begin{array}{l}\text { Perceived behavioral control (BC) } \\
\text { (Taylor \& Todd, 1995; Bhattacherjee, 2000) }\end{array}$} & $\mathrm{BC} 1$ & $\begin{array}{l}\text { My knowledge and resources are sufficient to use } \\
\text { e-invoice }\end{array}$ \\
\hline & $\mathrm{BC} 2$ & I have ability to use e-invoice \\
\hline & BC3 & Using e-invoice is under my control \\
\hline \multirow{3}{*}{$\begin{array}{l}\text { Intention to use (INT) } \\
\text { (Davis, 1989) }\end{array}$} & INT1 & I intent to adopt e-invoice \\
\hline & INT2 & I will regularly use e-invoice \\
\hline & INT3 & It is possible that I will continue to use e-invoice \\
\hline
\end{tabular}




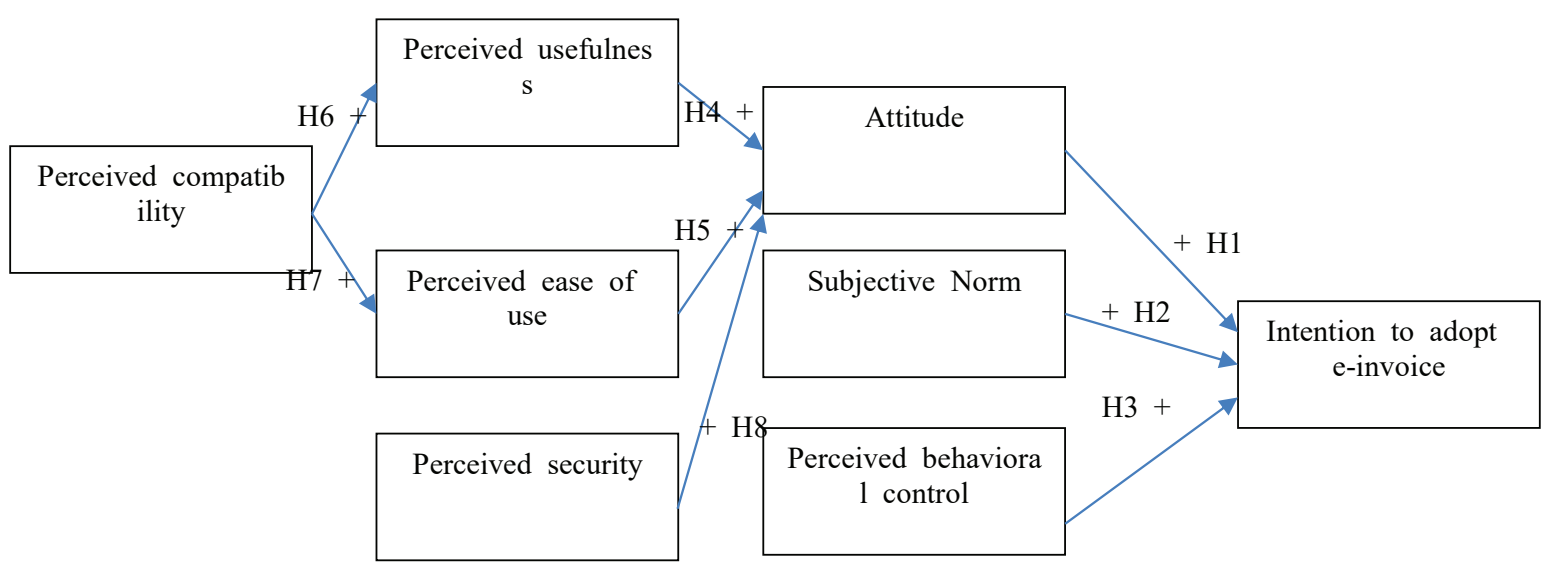

Figure 1: Research model

validity are assessed to confirm that scales are not skewed due to measurement errors. Firstly, the measurement model is considered to be fit with market data if GFI, TLI, CFI > 0.9, Chi-square/df $\leq 3$, RMSEA $<0.08$ (Henry \& Stone, 1994). Secondly, the reliability of the scales is assessed by composite reliability (CR) which should be larger than 0.7 (Fornel \& Larcker, 1981). Secondly, unidimensionality is examined to evaluate whether items forming scales measure only a single construct (Brentari \& Golia, 2007). The items of measurements are assessed unidimensionality only if there is no correlation between measurement errors of the observed variables. Thirdly, convergent validity is satisfied if AVE of each factor larger than 0.5 (Fornel \& Larcker, 1981). Finally, discriminant validity is assessed by comparing the amount of square root AVE and the correlation between factors. Fornel and Larcker (1981) suggested that square root AVE should be greater than the correlations.

Structural equation modeling (SEM) is employed to estimate the model and test the proposed hypotheses. The goodness of fit of the structural model is measured by Chisquare/df, CFI, GFI and RMSEA indices. Hair, Black, Babin and Anderson (2009) suggested that the model fits the data if Chi-square/df $<3$, CFI and GFI $\geq 0.9$, RMSEA $<0.08$.

\section{Results and Discussion}

\subsection{Results}

\subsubsection{Cronbach's Alpha Analysis}

The results suggest that all variables are considered to be reliable since their corrected item-total correlation $>0.3$ and Cronbach's alpha $>0.6$, except PEOU 4 (of which corrected item-total correlation $<0.3$ ). Therefore, Cronbach's Alpha analysis is performed for PEOU variable after removing item PEOU4. The result is acceptable since any item of PEOU has corrected item-total correlation $>0.3$ and Cronbach's Alpha coefficient $>0.6$.

\subsubsection{EFA Analysis}

The initial results of EFA analysis are shown the observed variables load on eight latent factors and each variable converges in a single factor, except for PU4 which loads on 2 factors. Since the differences between two loading factors are smaller than 0.3, this variance is not acceptable. EFA analysis is performed after eliminating the PU4 variable.

The results of EFA, after deleting PU4 variables, are acceptable since each observed variable converges in only one factor with loading factor larger than 0.5. Cumulative Variances of factors indicate that the variables explain $60.604 \%$ factors. The $\mathrm{KMO}=0.75$ at $\mathrm{p}$-value of 0.000 which presenting for $100 \%$ reliability. Therefore, EFA analysis results after eliminating PU4 indicate the consistency and suitability of research data (see Table 2).

\subsubsection{CFA Analysis}

CFA analysis results indicate a good fit of measurements since Chi-square/df $=1.68<2$, TLI, CFI, GFI are larger than $0.9(0.936,0.947,0.906$ respectively $)$, RMSEA = $0.046<0.5$. There is no correlation among measurement errors of observed variables, therefore the unidimensionality of variables is identified. The results of the reliability, convergent validity, and discriminant validity analyses are shown in Table 3 . The CR of variables ranges from 0.763 to 0.875 (larger than 0.7 ), and AVE ranges from 0.522 to 0.7 (greater than 0.5), therefore the measurements are ensured 
Table 2: The result of EFA after eliminating factor

\begin{tabular}{|c|c|c|c|c|c|c|c|c|}
\hline \multirow[t]{2}{*}{ Variables } & \multicolumn{8}{|c|}{ Factor } \\
\hline & 1 & 2 & 3 & 4 & 5 & 6 & 7 & 8 \\
\hline AB1 & 0.852 & & & & & & & \\
\hline AB4 & 0.803 & & & & & & & \\
\hline AB3 & 0.794 & & & & & & & \\
\hline AB2 & 0.719 & & & & & & & \\
\hline PC1 & & 0.879 & & & & & & \\
\hline PC2 & & 0.852 & & & & & & \\
\hline PC3 & & 0.778 & & & & & & \\
\hline SN1 & & & 0.856 & & & & & \\
\hline SN3 & & & 0.789 & & & & & \\
\hline SN2 & & & 0.735 & & & & & \\
\hline PEOU3 & & & & 0.807 & & & & \\
\hline PEOU2 & & & & 0.782 & & & & \\
\hline PEOU1 & & & & 0.705 & & & & \\
\hline $\mathrm{BC} 3$ & & & & & 0.819 & & & \\
\hline $\mathrm{BC} 1$ & & & & & 0.682 & & & \\
\hline $\mathrm{BC} 2$ & & & & & 0.679 & & & \\
\hline PU1 & & & & & & 0.819 & & \\
\hline PU2 & & & & & & 0.793 & & \\
\hline PU3 & & & & & & 0.59 & & \\
\hline INT3 & & & & & & & 0.851 & \\
\hline INT1 & & & & & & & 0.729 & \\
\hline INT2 & & & & & & & 0.585 & \\
\hline PS1 & & & & & & & & 0.83 \\
\hline PS2 & & & & & & & & 0.762 \\
\hline PS3 & & & & & & & & 0.542 \\
\hline Eigenvalues & 4.562 & 3.26 & 2.529 & 2.072 & 1.541 & 1.54 & 1.435 & 1.298 \\
\hline $\begin{array}{l}\text { Cumulative } \\
\text { Variance (\%) }\end{array}$ & 16.855 & 28.174 & 36.81 & 43.489 & 48.105 & 52.651 & 56.918 & 60.604 \\
\hline $\mathrm{KMO}=0.75$ & & & & & & sig. & 000 & \\
\hline
\end{tabular}

Table 3: Results of reliability, convergent validity and discriminant validity analyses in CFA

\begin{tabular}{|l|c|c|c|c|c|c|c|c|c|c|}
\hline Variables & \multirow{2}{*}{ CR } & AVE & \multicolumn{7}{|c|}{ Factor correlations } \\
\cline { 4 - 11 } & & & INT & AB & PC & SN & PEOU & BC & PU & PS \\
\hline INT & 0.783 & 0.546 & - & & & & & & & \\
\hline AB & 0.871 & 0.628 & .201 & - & & & & & & \\
\hline PC & 0.875 & 0.700 & .007 & .486 & - & & & & & \\
\hline SN & 0.835 & 0.628 & .092 & .099 & .149 & - & & & & \\
\hline PEOU & 0.814 & 0.594 & .106 & .232 & .189 & .299 & - & & & \\
\hline BC & 0.778 & 0.539 & .381 & .054 & .040 & .088 & .172 & - & & \\
\hline PU & 0.778 & 0.543 & .094 & .304 & .350 & .128 & .056 & .117 & - & \\
\hline PS & 0.763 & 0.522 & .289 & .108 & .119 & .073 & .013 & .249 & .010 & - \\
\hline Highest correlation coefficient & 0.381 & 0.486 & 0.486 & 0.299 & 0.299 & 0.381 & 0.350 & 0.289 \\
\hline$\sqrt{A \text { AVE }}$ & & 0.739 & 0.792 & 0.837 & 0.792 & 0.771 & 0.734 & 0.737 & 0.722 \\
\hline
\end{tabular}


reliability and convergent. The discriminant validity is acceptable since root square AVE values are above any values of correlation with constructs. Thus, it can be concluded that the measurement model has a high degree of reliability, convergent validity and discriminant validity.

\subsubsection{SEM Analysis}

CFA analysis results indicate that the requirements of constructs reliabilility, unidimensionality, as well as convergent and discriminant validities, are satisfied. Therefore, the causal structure of the estimated model can be assessed by SEM. The assessed model achieves Chi-square $/ \mathrm{df}=1.951<3$, TLI $=0.91$ $>0.9, \mathrm{CFI}=0.92>0.9, \mathrm{RMSEA}=0.055<0.08$ which are under the threshold values of fitness indices. Although GFI score does not exceed $0.9(0.886)$, it is still under the requirement suggested by some researches such as Baumgartner and Homburg (1996), Henry and Stone (1994). The value of GIF is acceptable if it is larger than 0.8 . Therefore, it can be concluded that the proposed model fits the observed data. Therefore, the path coefficients can be examined to detect any initial hypothesis that maybe not relevant to the model.

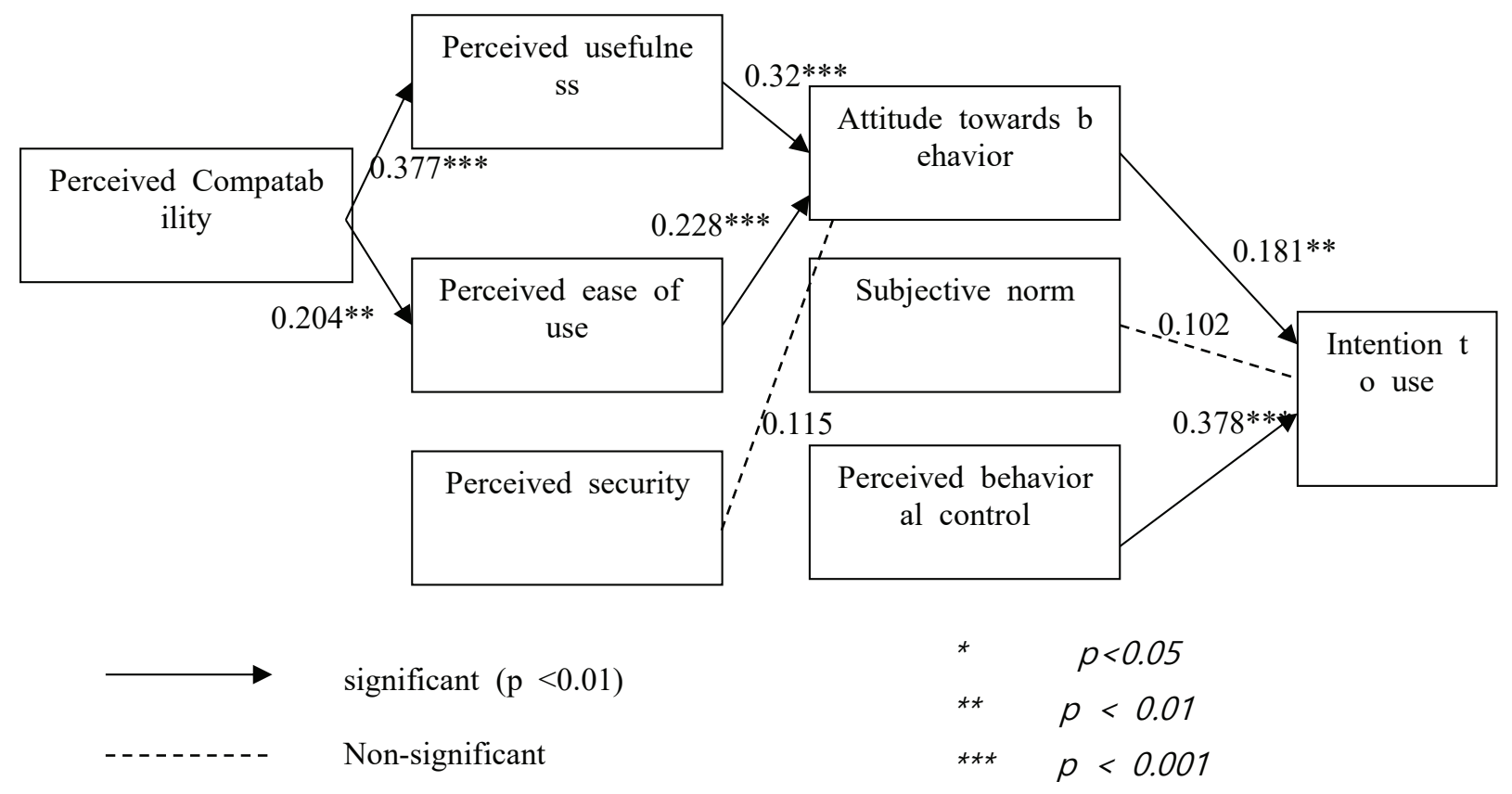

Figure 2. Summarized results of hypotheses testing for e-invoice adoption in Vietnam

The standardized path coefficients are presented in Figure 2. All parameters are significant at 0.01 and 0.001 levels except for those paths of PS to AB and SN to INT. Thus, hypothesis $\mathrm{H} 2$ and hypothesis $\mathrm{H} 8$ are rejected while the other hypotheses are supported.

\subsubsection{Bootstrap Analysis}

A bootstrap analysis is performed to evaluate the reliability of the model's estimation by resampling an original dataset with replacement. The critical ratios (CR) of all variables are less than 1.96 when the numbers of bootstrap samples are 500. Therefore, it can be concluded that the estimated model is reliable (see Table 4).

\subsection{Discussion}

The results of SEM analysis support all hypotheses except $\mathrm{H} 4$ and H8. The supported hypotheses H1 and H3 indicate that intention to use e-invoice in Vietnam is jointly affected by an attitude towards behavior $(\beta=0.181)$ and perceived behavioral control $(\beta=0.378)$. The results are in line with the finding of Wu and Chen (2005) and Taylor and Todd (1995). Among these effects, perceived behavioral produces a more significant impact on intention rather than attitude towards behavior. Therefore, when users perceive they obtain enough resources, abilities, and control, it is likely that they would adopt e-invoice or continue to use e-invoice in the future. 
Anh Huu NGUYEN, Thao Phuong NGUYEN, Giang Tra Thi DANG /

Table 4: Results of bootstrap analysis $(\mathrm{N}=500)$

\begin{tabular}{|c|c|c|c|c|c|c|c|c|}
\hline \multicolumn{3}{|c|}{ Parameters } & SE & SE-SE & Mean & Bias & SE-Bias & C.R \\
\hline PU & $<---$ & PC & 0.079 & 0.003 & 0.374 & -0.003 & 0.004 & -0.75 \\
\hline PEOU & $<---$ & PC & 0.064 & 0.002 & 0.199 & -0.005 & 0.003 & -1.66667 \\
\hline AB & $<---$ & PS & 0.064 & 0.002 & 0.11 & -0.005 & 0.003 & -1.66667 \\
\hline AB & $<---$ & PU & 0.077 & 0.002 & 0.319 & -0.001 & 0.003 & -0.33333 \\
\hline AB & $<---$ & PEOU & 0.064 & 0.002 & 0.226 & -0.002 & 0.003 & -0.66667 \\
\hline INT & $<---$ & AB & 0.067 & 0.002 & 0.176 & -0.005 & 0.003 & -1.66667 \\
\hline INT & $<---$ & SN & 0.064 & 0.002 & 0.099 & -0.003 & 0.003 & -1 \\
\hline INT & $<---$ & BC & 0.071 & 0.002 & 0.373 & -0.005 & 0.003 & -1.66667 \\
\hline
\end{tabular}

The hypothesis $\mathrm{H} 2$ about subjective norm's effect on the intention to behavior is rejected. This result is comparable with the results of Taylor and Todd (1995) and Wu and Chen (2005), but differs from the findings by Bhattacherjee (2000), Gopi and Ramayah (2007), Ajzen (2015) and Lian (2015). It can be explained by the fact that adoption of e-invoice is different from that of e-service (Bhattacherjee, 2000), online trading (Gopi and Ramayah, 2007), online course and food consumption (Ajzen, 2015). In particular, e-invoice in this study is at the initial stage of adoption, therefore reviews and references of friends, peers or superiors maybe not be sufficient. Consequently, the social pressure is not perceived, which causes the insignificant effect of subjective norm on the intention to adopt e-invoice in Vietnam.

The hypotheses $\mathrm{H} 4$ and $\mathrm{H} 5$ related to impacts of perceived usefulness and perceived ease-of-use to attitude to behavior are supported. Prior studies have shown the same results such as $\mathrm{Wu}$ and Chen (2005), Renny, Guritno and Siringoringo (2013). The effect of perceived usefulness $(\beta=0.32)$ is higher than the effect of perceived ease-of-use $(\beta=0.228)$ on user's attitude towards adopting e-invoice. Plausibly, potential users need to appreciate the usefulness and the easeof-use to build a positive attitude. Consequently, favorable attitude towards e-invoice implies a critical influence on the intention to use e-invoice. However, due to the fact that e-invoice has been adopted voluntarily in this infant stage of adoption, it may cost more than a paper invoice in order to develop sufficient IT infrastructure to process e-invoice. Therefore, the observed variable PU 4 (Costs of processing transactions are optimized by using e-invoice) is considered to be irrelevant as implied in the result of EFA analysis.

The supported hypotheses H6 and H7 imply the explanatory power of perceived compatibility to perceived usefulness and perceived ease-of-use. These results are consistent with the research by Kanchanatanee, Suwanno and Jarernvongrayab (2014) and Ismail (2016). The effect of perceived compatibility on perceived usefulness $(\beta=0.377)$ is higher than this one on perceived ease of use (0.204). It can be explained that users will feel more familiar and comfortable to adopt e-invoice if e-invoice is in accordance with their values, cultures, and activities. Therefore, the awareness of usefulness and the degree of ease to adopt e-invoice is positively impacted.

Finally, hypothesis $\mathrm{H} 8$ that proposes the positive relationship between perceived security and attitude towards behavior is rejected. This result is similar to the research by Jun and Jaafar (2011). It implies that the perception of e-invoice does not impact user's attitude towards adopting e-invoice. Security is one of the requirements needed to be complied with when e-invoice is developed. Therefore, security is a necessary characteristic of e-invoice, which cannot be omitted. It is probably that users are not concerned about this factor since it is the indispensable nature of e-invoice. Therefore, perceived security is not an important factor influencing user's attitude towards adopting e-invoice.

\section{Recommendations and Conclusion}

\subsection{Recommendations}

The research findings probably contribute to practical and theoretical implications. Firstly, some practicable suggestions are proposed in order to boost the number of enterprises voluntarily adopting e-invoice. This study indicates the important impacts of the user's attitude and perception about control ability on intention to use. In order to enhance the favorable attitude towards e-invoice, the usefulness and effortless use of e-invoice need to be carefully paid attention to. It is suggested that invoicing software should be consistent with existing accounting system for companies. E-invoice should be based on varied formats, which can be integrated directly into the consumer or supplier's recording system. Additionally, it is necessary to enhance the compatibility of e-invoice with the resources 
and activities of enterprise. Therefore, the designing contents of e-invoice should be flexible, but still ensure the necessary information to suit different types of businesses. Nevertheless, Vietnamese authorities should propose more detailed guidance and manuals, which help enterprises get on the right track of adopting e-invoice in the future. Secondly, the research results also indicate some theoretical implications. This paper provides more insight into the determinants of e-invoice adoption in terms of individuals by combining IDT, TAM and TPB models. This approach may be incorporated in the literature that focuses on behavior research in the future.

\subsection{Conclusion}

This study proposes a new model combining the IDT, TAM and TPB models to investigate the determinants of e-invoice adoption in Vietnam while at the infant stage. A sample of 318 responses from accountants and managers of enterprises in Vietnam was employed to assess the proposed model. The results imply the joint impact of attitude towards behavior and perceived behavioral control on the intention to use e-invoice. Attitude towards behavior, in turn, is determined by perceived usefulness and perceived ease-of-use. Perceived compatibility is also an important factor that influences both perceived usefulness and perceived ease-of-use.

\section{References}

Ajzen, I. (1991). The theory of planned behavior. Organisational Behavior and Human Decision Processes, 50(2), 179-211.

Ajzen, I. (2015). Consumer attitudes and behavior: the theory of planned behavior applied to food consumption decisions, Rivista di Economia Agraria, 70(2), 121-138.

Baumgartner, H., \& Homburg, C. (1996). Applications of structural equation modeling in marketing and consumer research: a review. International Journal of Research in Marketing, 13(2), 139-161.

Bhattacherjee, A. (2000). Acceptance of e-commerce services: the case of electronic brokerages, IEEE Transaction on System, Man, and Cybernetics - Part A: System and Humans, 30(4), 411-420.

Brentari, E., \& Golia, S. (2007). Undimensionality in the rasch model: how to detect and interpret. Statistica, 67(3), 253-261.

Davis, F. D. (1989). Perceived usefulness, perceived ease of use, and user acceptance of information technology, MIS Quarterly, 13(3), 319-340.

Davis, F.D., Bagozzi, R., \& Warshaw, P.R. (1989). User acceptance of computer technology: a comparison of two theoretical models. Management Science, 35(8), 982-1003.

Dawes, J. (2008). Do data characteristics change according to the number of scale points used? An experiment using 5 point, 7 point and 10 point scales, International Journal of Market Research, 50(1) 61-104.
Dnishev, F. \& Alzhanova, F. (2016). Globalization of technological development and opportunities for national innovation systems of developing countries. Journal of Asian Finance, Economics and Business, 3(4), 67-79. https://doi.org/10.13106/jafeb.2016. vol3.no4.67

Fornell, C., Larcker, D.F. (1981). Evaluating structural equation models with unobservable variables and measurement errors. Journal of Marketing Research, 18(1), 39-50.

Gopi, M., Ramayah, T. (2007). Applicability of theory of planned behavior in predicting intention to trade online: some evidence from a developing country. International Journal of Emerging Markets, 2(4), 348-360.

Ha, V. D. (2020). Impact of organizational culture on the accounting information system and operational performance of small and medium sized enterprises in Ho Chi Minh City. Journal of Asian Finance, Economics and Business, 7(2), 301-308. https:// doi.org/10.13106/jafeb.2020.vol7.no2.301

Hair, J. F., Black, W. C., Babin, B. J., \& Anderson, R. E. (2009). Multivariate Data Analysis (7th ed.). Upper Saddle River, NJ: Prentice Hall Press.

Henry, J.W., \& Stone, R.W. (1994). A structural equation model of end-user satisfaction with a computer-based medica information systems. Information Resources Management Journal, 7(3), 21-33.

Hernandez-Ortega, B. (2012). Key factors for the adoption and subsequent use of e-invoicing. Academia. Revista Latinoamericana de Administración, 50, 15-30.

Ismail, H.A. (2016). Intension to use smartphone through perceived compatibility, perceived usefulness, and perceived ease of use. Jurnal Dinamika Manajemen, 7(1), 1-10.

Jain, V., \& Ajmera, P. (2018). Quantifying the variables affecting Indian medical tourism sector by graph theory and matrix approach, Management Science Letters, 8, 225-240.

Jun, G., Jaafar, N.I. (2011). A study on consumers' attitude towards online shopping in China. International Journal of Business and Social Science, 2 (22), 112-132.

Kanchanatanee, K., Suwanno, N., \& Jarernvongrayab, A. (2014). Effects on attitude toward using, perceived usefulness, perceived ease of use and perceived compatibility on intention to use e-marketing. Journal of Management Research, 6(3), $1-13$.

Kassim, N.A. (2017). Information needs of Malaysian Bumiputera would-be entrepreneurs, Malaysian Journal of Library \& Information Science, 15(2), 57-69.

Kolodinsky, J.M., Hogarth, J.M., \& Hilgert, M. (2004). The adoption of electronic banking technologies by US consumers. The International Journal of Bank Marketing, 22(4), 238-259.

Kumpajaya, A., \& Dhewanto, W. (2015). The acceptance of bitcoin in Indonesia: extending TAM with IDT. Journal of Business and Management, 4(1), 28-38.

Lian, J.W. (2015). Critical factors for cloud based e-invoice service adoption in Taiwan: an empirical study. International Journal of Information Management, 35(1), 96-109. 
Nguyen, A.H., Ha, H.H., \& Nguyen, S.L. (2020). Determinants of information technology audit quality: evidence from Vietnam. Journal of Asian Finance, Economics and Business, 7(4), 4150. https://doi.org/10.13106/jafeb.2020.vol7.no4.41

Nguyen, T.T.D., Pham, T.M.L., Le, T.T., Truong, T.H.L., \& Tran, M.D. (2020). Determinants influencing tax compliance: the case of Vietnam. Journal of Asian Finance, Economics and Business, 7(2), 65-73. https://doi.org/10.13106/jafeb.2020. vol7.no2.65

Nunnally, J. C., \& Bernstein, I. H. (1994). Psychometric Theory (3rd ed.). New York: McGraw-Hill Press.

O'Cass, A., \& Fenech, T. (2003). Web retailing adoption: exploring the nature of internet users web retailing behavior. Journal of Retailing Consumer Services, 10, 81-94.

Pikkarainen, T., Pikkarainen, K., Karjaluoto, H., \& Pahnila, S. (2004). Consumer acceptance of online banking: an extension of the technology acceptance model. Internet Research, 14(3), 224-235.

Premkumar, G., Roberts, M. (1999). Adoption of new information technologies in rural small businesses, OMEGA. The International Journal of Management Science, 27(4), 467-484.

Quaddusa, M., \& Achjari, D. (2005). A model for electronic commerce success. Telecommunications Policy, 29(2-3), 127152.

Rahi, S., Ghani, M.A., Alnaser, F. M.I. \& Ngah, A.H. (2018). Investigating the role of unified theory of acceptance and use of technology (UTAUT) in internet banking adoption context. Management Science Letters, 8, 173-186.

Ranganathan, S., Ganapathy, C. (2002). Key dimensions of business-to-consumer web sites. Information \& Management, $39(6), 457-465$.

Renny, Guritno, S., Siringoringo, H. (2013). Perceived usefulness, ease of use, and attitude towards online shopping usefulness towards online airline ticket purchase. Procedia-Social and Behavioral Sciences, 81, 212-216.
Rogers, E.M. (1995). Diffusion of Innovations (4th ed.). New York: Free Press.

Samad, S. (2018). Theory of planned behavior and knowledge sharing among nurses in patient computer management system: the role of distributive justice. Management Science Letters, 8 , 427-436.

Taylor, S., Todd, P.A. (1995). Understanding information technology usage: a test of competing models, Information Systems Research, 6(2), 144-176.

Teo, T. S. H. (2001). Demographic and motivation variables associated with Internet usage activities. Internet research, $11(2), 125-137$.

Tuan, N.A., Thanh, N.M., \& Loc, T.T. (2018). Technology management and challenges of Vietnamese enterprises in the international market. Journal of Asian Finance, Economics and Business, 5(1), 43-52. https://doi.org/10.13106/jafeb.2018. vol5.no1.43

Venkatesh, V., Davis, F.D. (1996). A model of the antecedents of perceived ease of use: development and test. Decision Science, 27(3), 451-481.

Venkatesh, V., Davis, F.D. (2000). A theoretical extension of the technology acceptance model: four longitudinal field studies. Management Science, 46(2), 186-204.

Venkatesh, V., Morris, M.G., Davis, G.B., \& Davis, F.D. (2003). User acceptance of information technology: Toward a unified view, MIS Quarterly, 27(3), 425-478.

Wu, I.L., Chen, J.L. (2005). An extension of trust and TAM model with TPB in the initial adoption of on-line tax: an empirical study. International Journal of Human-Computer Studies, 62(6), 784-808.

Yanamandram, V., \& White, L. (2006). Switching barriers in business-to-business services: a qualitative study. International Journal of Service Industry Management, 17(2), 158-192.

Yousafzai, S.Y., Pallister, J.G., \& Foxall, G.R. (2003). A proposed model of e-trust for electronic banking, technovation. Management Science Letters, 23(11), 847-860. 